\title{
Menakar Level Literasi Low Carbon Siswa Sekolah Dasar dalam Aktivitas Kehidupan Sehari-Hari
}

\author{
M. Syahruddin Amin*, Anna Permanasari, Agus Setiabudi, Ida Hamidah \\ ${ }^{1}$ Pendidikan IPA, Sekolah Pascasarjana, Universitas Pendidikan Indonesia \\ *E-mail: amien_syahruddin@upi.edu
}

\begin{abstract}
Abstrak
Tingginya emisi $\mathrm{CO}_{2}$ yang terbuang ke atmosfer memunculkan permasalahan pada lingkungan yaitu pemanasan global dan perubahan iklim. Pola hidup manusia yang tidak ramah lingkungan semakin memperparah kerusakan lingkungan. Menanamkan karakter peduli lingkungan harus dilakukan, pendidikan bisa menjadi salah satu cara untuk melakukan itu. Rumusan masalah dalam penelitian ini adalah bagaimanakah gambaran literasi low carbon siswa sekolah dasar di Kabupaten Lombok Timur, Nusa Tenggara Barat? Penelitian deskriptif ini bertujuan untuk mengetahui derajat pemahaman siswa sekolah dasar tentang pemanasan global dan emisi $\mathrm{CO}_{2}$ dalam hidup keseharian mereka. Penelitian ini menggunakan metode survey menggunakan kuisioner. Hasil penelitian menunjukkan derajat literasi low carbon siswa kelas 3 masih lebih rendah dibandingkan siswa kelas 6 . Hal itu terlihat pada konteks aktivitas yang terkait dengan penggunaan energi seperti mematikan alat listrik, pemanfaatan air, dan sampah terutam plastik. Secara umum dapat disimpulkan bahwa literasi siswa SD di Lombok Timur berada pada level baik, dan sebagian besar siswa telah mampu mengaplikasikan nilai low carbon education dalam aktivitas hidup sehari-hari mereka.
\end{abstract}

Kata kunci: low carbon education, literasi low carbon

\section{PENDAHULUAN}

Memasuki era milenium ketiga, tingkat persaingan makin ketat, ekonomi bertumbuh dengan cepat, perkembangan teknologi berlangsung sangat pesat, inovasi baru terus bermunculan, penggunaan mesin hampir merata diseluruh sendi kehidupan. Energi merupakan bahan bakar yang menggerakkan roda kemajuan dan pertumbuhan ekonomi tersebut. Konsumsi energi terutama bahan bakar fosil meningkat secara drastis semenjak pertengahan abad 20 dan meningkat terus sampai sekarang. Secara global, bahan bakar fosil merupakan energi utama mencapai $80 \%$ dari keseluruhan konsumsi energi (Mardani, Streimikiene, Cavallaro, Loganathan, \& Khoshnoudi, 2019). Energi terbesar yang digunakan untuk mengoperasikan teknologi dan menjalankan kehidupan dunia saat ini sebagian besar diambil dari sumber energi tak terbarukan seperti minyak bumi dan batu bara. Jumlahnya terus meningkat bahkan diproyeksikan eksploitasi akan terjadi hingga tahun 2040 (Capuano, 2018; BP Energy, 2018). Pemanasan global dan perubahan iklim muncul menjadi fakta tak terelakkan, menjelma menjadi masalah terbesar dan utama lingkungan hingga saat ini. Penyebabnya adalah tingginya kandungan gas rumah kaca terutama $\mathrm{CO}_{2}$ di atmosfer. Dalam laman berita liputan6.com tertulis Global Carbon Project (GCP) melaporkan bahwa emisi karbon global mengalami peningkatan pada tahun 2017 yakni sekitar $2 \%$ dibandingkan tahun 2016, dengan besaran sekitar 37 miliar ton $\mathrm{CO}_{2}$. Data secara global menunjukkan bahwa rata-rata kenaikan suhu permukaan bumi dalam 140 tahun sebesar $0,85^{\circ} \mathrm{C}$ dan permukaan air laut naik setinggi $225 \mathrm{~mm}$, dan konsentrasi gas karbon dioksida secara global saat ini merupakan yang tertinggi dalam 800.000 tahun (Dawson, 2015). Kondisi ini akan mengakibatkan terjadinya pemanasan global dan perubahan iklim yang pada tahap selanjutnya akan memicu terjadinya anomali cuaca bahkan kepunahan spesies makhluk hidup (M. S. Amin, Permanasari, \& Setiabudi, 2019). Pada tahap selanjutnya, kondisi ini akan memicu timbulnya 
berbagai masalah baik itu berupa geopolitik akibat dari pergeseran garis pantai, meingkatnya potensi bencana alam seperti banjir, badai, angin topan, gelombang ekstrem, tsunami, abrasi, dsb.

Namun, bila kita cermati lebih dalam maka penyebab sesungguhnya peningkatan kadar $\mathrm{CO}_{2}$ diatmosfer, pemanasan global, dan berbagai kerusakan lingkungan lainnya adalah pola hidup manusia yang tidak ramah lingkungan seperti membuang sampah, membakar sampah dan lahan, dan perilaku boros energi dan listrik. Perilaku ini merupakan indikasi bahwa kesadaran dan kepedulian masyarakat terhadap lingkungan masih rendahnya. Berkaca pada kondisi kerusakan lingkungan dan bencana lingkungan yang sudah terjadi pada saat ini, membangun kesadaran dan kepedulian masyarakat terhadap pentingnya menjaga lingkungan dan mempertahankan keberlangsungan kehidupan menjadi sesuatu yang penting dan segera untuk dilakukan. Maka mengembangkan literasi low carbon dalam diri setiap orang khususnya siswa menjadi hal yang sangat penting, karena keberlangsungan alam di masa yang akan datang sangat bergantung pada pengetahuan dan kepedulian mereka terhadap alam.

Pendidikan sebagai salah satu bagian utuh sistem sosial kehidupan masyarakat merupakan sarana terbaik untuk menumbuhkan dan membangun kesadaran dan kepedulian masyarakat terhadap lingkungan. Pendidikan dasar merupakan fondasi awal untuk membangun literasi low carbon dalam diri peserta didik. La Trobe \& Acott menyatakan bahwa permasalahan lingkungan tidak bisa diselesaikan hanya dengan mengatasi kerusakan lingkungan semata, jauh lebih penting adalah merubah mindset dan membangun kesadaran masyarakat termasuk pelajar untuk ikut berkontribusi dalam upaya pengelolaan lingkungan (Amini, 2015). Dengan kata lain, mengajarkan isu dan materi lingkungan menjadi sangat penting dalam dunia pendidikan (Gola, 2017). Melalui belajar tentang lingkungan siswa akan mendapatkan pengetahuan mengenai realita lingkungan, dan juga mengembangkan kesadaran dan rasa pedulinya terhadap lingkungan. Menanamkan karakter atau wawasan tentang lingkungan semestinya dilakukan sedini mungkin, mulai dari tingkat pendidikan terendah (Priyatna, Meilinawati, \& Subekti, 2017). Aplikasi dalam pendidikan bisa diwujudkan dalam banyak hal mulai dari kurikulum berbasis lingkungan, penyiapan sarana pendukung berwawasan lingkungan semisal tempat sampah yang terpilah, dan melakukan pembelajaran di luar kelas semisal membuat kompos atau biopori (Afriyeni, 2018). Setidaknya terdapat 5 pokok bahasan utama dalam mengajarkan tentang lingkungan yaitu lingkungan sosial, lingkungan spasial, lingkungan alam, lingkungan buatan, serta perubahan iklim dan bencana lingkungan (Hamzah, 2013).

Penyumbang terbesar gas rumah kaca di atmosfer adalah emisi $\mathrm{CO}_{2}$ yang sumbe utamanya adalah dari konsumsi energi fosil. Pada saat ini, Indonesia merupakan negara dengan konsumsi energi terbesar dikawasan Asia Tenggara, dan urutan kelima dikawasan Asia Pasifik dalam konsumsi energi primer setelah China, India, Jepang, dan Korea Selatan (BPPT, 2018). Mengacu pada fakta tersebut, maka semestinya orientasi dan substansi utama pengajaran lingkungan dalam pendidikan harus difokuskan pada materi yang berkenaan dengan substansi low carbon education, serta diarahkan untuk mengembangkan literasi low carbon siswa.

Membangun pengetahuan dan kesadaran mengenai energi dan tata kelola energi agar lebih ramah lingkungan harus menjadi fokus utama proses pendidikan terutama low carbon education. Makna dasar dari low carbon adalah tingkat emisi $\mathrm{CO}_{2}$ yang rendah. Low carbon education adalah suatu tindakan untuk mewujudkan sebuah low carbon society melalui sistem pendidikan berkelanjutan yang dimulai dari sekolah dan keluarga. Esensi utamanya adalah efisiensi penggunaan energi, pengembangan clean energy, dan mendorong tercapainya green development (Zheng, Zhou, \& Shi, 2014), dan juga manajemen penggunaan material yang berpengaruh terhadap lingkungan (Paige, 2016). Tujuannya adalah memberikan pengetahuan, mengembangkan kesadaran dan kepedulian, serta keterampilan yang berkaitan dengan 
substansi low carbon dalam mengelola lingkungan dalam konteks hidup sehari-hari dalam skal individu maupun komunitas, seperti penggunaan energi (bahan bakar, listrik) dan konsumsi material alam (Xiaowei \& Xing, 2011), pengelolaan sumber daya alam, konservasi air, serta pengolahan sampah dan limbah. Dengan kata lain, low carbon education merupakan sarana membangun literasi low carbon dalam diri setiap individu. Literasi low carbon merupakan kemampuan individu untuk memahami tentang fenomena lingkungan khususnya pemanasan global dan membuat keputusan serta tindakan yang tepat untuk mengatasi dan memperbaiki kondisi lingkungan. Terdapat beberapa komponen yang terlibat didalamnya antara lain pengetahuan, kepedulian, perilaku, dan penerapan. Penelitian sebelumnya mendapati bahwa aspek penerapan dan kepedulian selalu lebih rendah dari aspek pengetahuan pada siswa dibeberapa jenjang pendidikan (Amin, Permanasari, \& Setiabudi, 2019). Rumusan masalah penelitian ini yaitu bagaimanakah gambaran literasi low carbon siswa sekolah dasar di Kabupaten Lombok Timur, Nusa Tenggara Barat?

\section{METODE PENELITIAN}

Penelitian deskriptif ini bertujuan untuk mengetahui derajat pemahaman siswa sekolah dasar tentang pemanasan global dan emisi $\mathrm{CO}_{2}$ yang diaplikasikan dalam perillaku kesehariannya. Metode yang digunakan pada penelitian ini adalah survey menggunakan instrumen kuisioner. Subyek dalam penelitian ini adalah siswa-siswi sekolah dasar di Kabupaten Lombok Timur, yang berjumlah 105 orang dengan rincian kelas 3 (58 orang) dan kelas 6 (47 orang). Kelas 3 dan 6 dipilih sebagai representasi dari kelas rendah dan kelas tinggi yang ada disekolah dasar, sehingga diharapkan data yang didapat akan lebih komprehensif. Kuisioner terdiri atas pertanyaan singkat yang terdiri atas 32 pertanyaan dengan rincian kelas 3 (18 pertanyaan) dan kelas 6 (14 pertanyaan), yang disusun dengan redaksi yang berbeda menyesuaikan dengan tingkat perkembangan siswa di masing-masing kelas namun tetap pada substansi yang sama. Kuisioner yang digunakan mencakup 4 substansi yaitu penggunaan istrik, penggunaan air, pengelolaan air dan sampah, serta penggunaan kendaraan bermotor. Jawaban siswa dianalisis menggunakan statistik deskriptif dan di interpretasi secara kualitatif untuk kemudian disusun secara sistematis menjadi informasi yang terstruktur.

\section{HASIL DAN PEMBAHASAN}

Optimalisasi peran pendidikan dalam upaya membangun pola hidup rendah emisi menjadi suatu kebutuhan bagi umat manusia untuk mempertahankan keberlangsungan kehidupannya dimasa depan. Menanamkan nilai-nilai dan prinsip low carbon pada generasi muda sejak usia dini merupakan langkah awal untuk mewujudkan pola hidup rendah karbon dan juga masyarakat ramah emisi di masa yang akan datang.

\section{Literasi Low Carbon Anak Usia \pm 9 Tahun (Kelas 3)}

Secara keseluruhan terlihat bahwa sebagian besar siswa telah menerapkan perilaku low carbon dalam aktivitas kesehariannya sebagaimana tergambar dalam diagram gambar 1 berikut ini: 


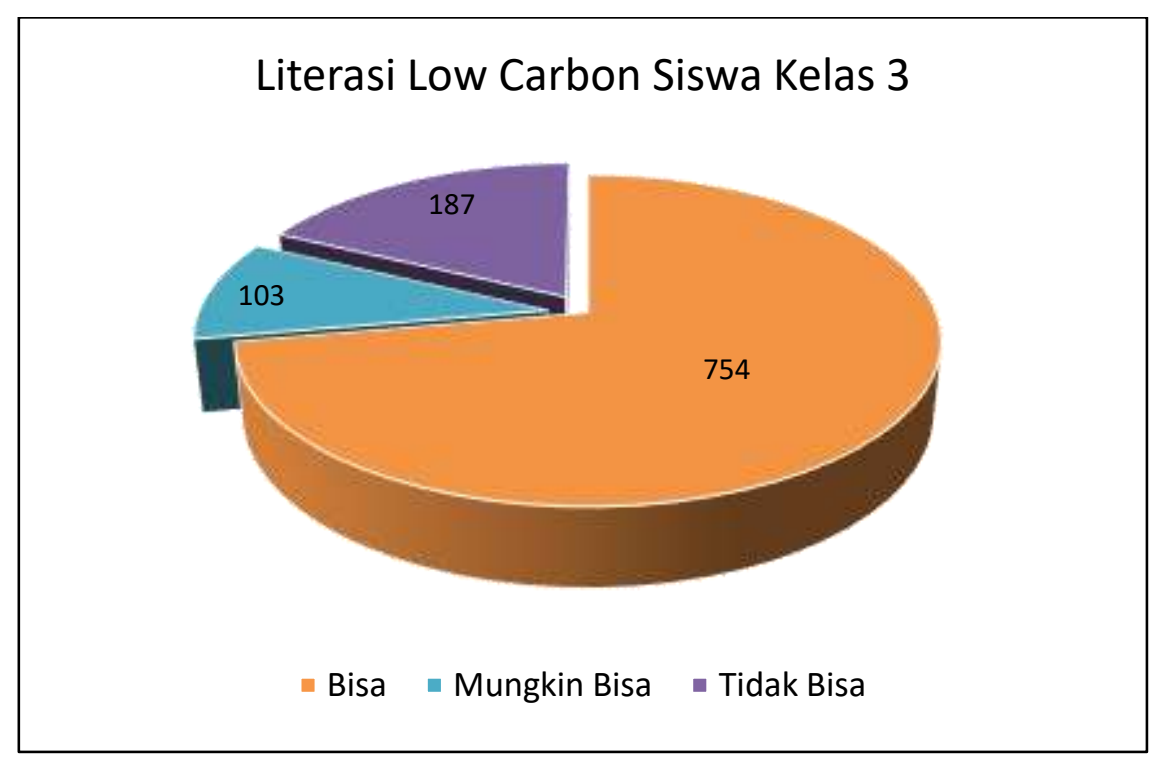

Gambar.1. Capaian literasi low carbon siswa kelas 3

Bahkan dalam beberapa hal yang berkenaan dengan penggunaan material (Paige, 2016) seperti menutup air keran ketika menggosok gigi (49 orang) dan mandi (48 orang), menaruh air di ember untuk mencuci kain pel (48 orang), tidak membuang pakaian bekas (48 orang) namun memanfaatkannya untuk aktivitas yang lain (47 orang), dan membuang kemasan makanan ditempatnya (47 orang) hampir semua siswa mempraktikkan perilaku low carbon tersebut. Demikian juga pada hal-hal yang terkait dengan penggunaan energi secara umum tingkat literasi siswa masih tinggi walaupun paling rendah dibandingkan dengan jenis aktivitas lainnya. Perilaku siswa pada beberapa aktivitas tersebut secara implisit menggambarkan sikap hemat energi dan bijak dalam memanfaatkan material yang merupakan aplikasi dari prinsip hemat energi untuk mengurangi emisi $\mathrm{CO}_{2}$ yang terbuang ke atmosfer dan prinsip reuse dalam upaya mengurangi volume sampah yang dibuang ke alam. Sedangkan pada konteks aktivitas yang lain seperti makanan, mainan, dan pemilahan sampah pencapaian literasi low carbon siswa kelas 3 rata-rata berada pada level baik. Gambaran detail capaian literasi low carbon siswa kelas 3 dapat dilihat pada gambar 2 berikut : 


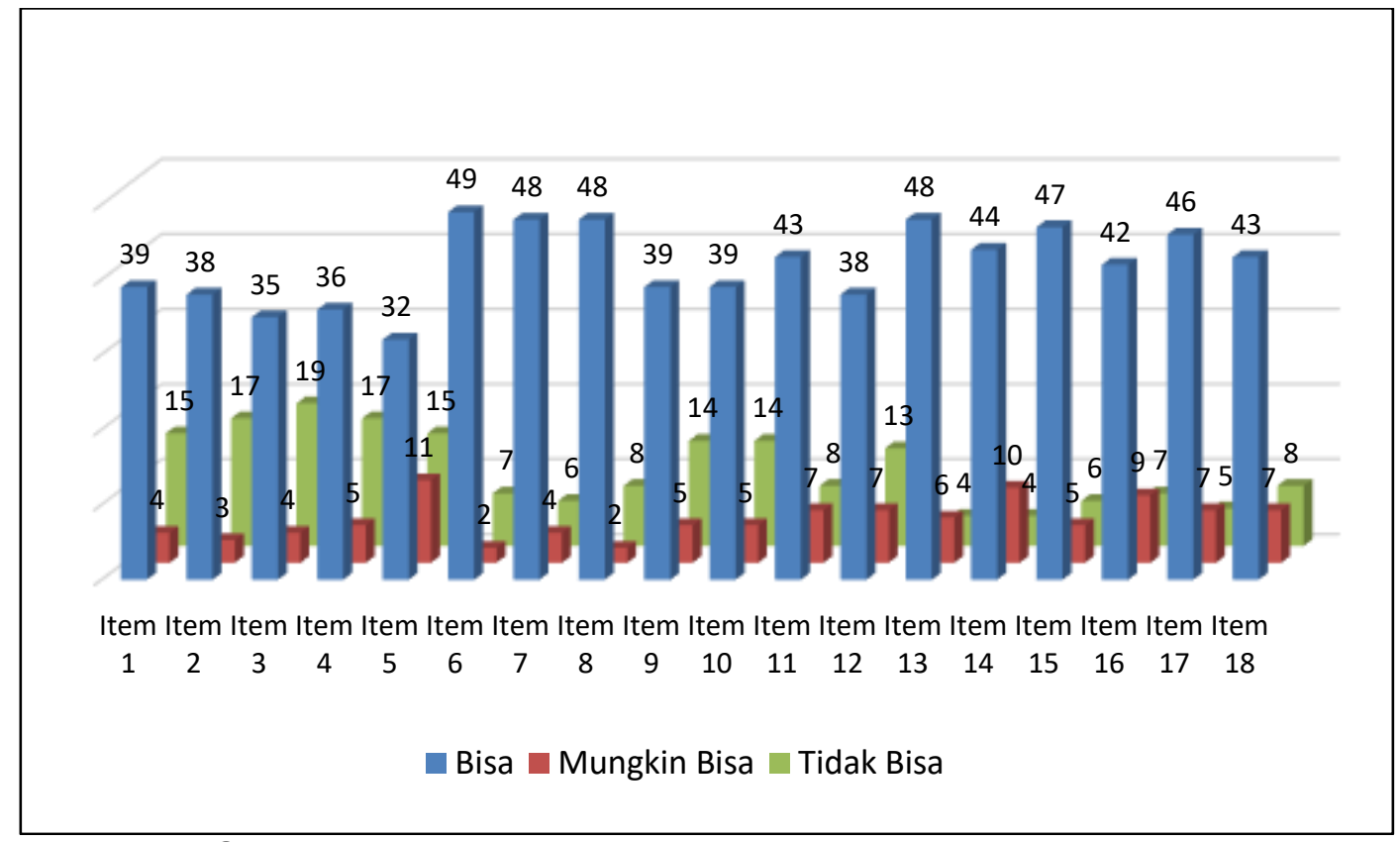

Gambar.2. Literasi low carbon siswa kelas 3 per item pertanyaan

Gambar diatas memperlihatkan bahwa hampir seluruh konteks aktivitas yang berkaitan dengan pengurangan emisi karbon maupun penghematan sumber daya/material dalam kehidupan telah mampu dilakukan oleh siswa. Selain itu, data juga memperlihatkan bahwa sebagian besar siswa kelas 3 pada seluruh aktivitas yang ditanyakan mampu mempraktikkan perilaku literasi low carbon dalam keseharian mereka. Namun pada beberapa konteks aktivitas terlihat masih ada cukup banyak siswa yang belum mampu mempraktikkan perilaku literasi low carbon dalam kesehariannya, seperti penggunaan energi (item 1-5), air (item 9 dan 10), dan sampah (item 12).

Pada aktivitas menutup kulkas (item 1) masih ada sekitar 32,7\% (19 siswa) yang masih lambat menutup kulkas setelah dibuka. Kemudian masih ada $31 \%$ siswa yang tidak mematikan AC saat keluar dari ruangan (item 2). Masih ada juga 39,6\% siswa yang membiarkan lampu ruangan tetap menyala walaupun tidak digunakan. Selanjutnya $37,8 \%$ siswa kelas 3 menonton televisi (item 4) dalam waktu yang lama dan $44,8 \%$ siswa yang bermain game (item 5 ) dalam durasi yang lama. Hal ini akan berkorelasi pada penggunaan energi listrik yang pastinya juga meningkatkan jumlah emisi $\mathrm{CO}_{2}$ ke atmosfer. Keberadaan perilaku ini pada anak juga tidak bisa kita lepaskan dari mudahnya akses anak terhadap televisi dan juga gadget. Penelitian di Australia pada 2010 mengungkap bahwa 1 dari 6 anak usia 6-7 tahun memiliki televisi dikamarnya sendiri (Nurcahyani, 2015). Selain itu, faktor konten tayangan yang banyak berupa animasi atau kartun juga ikut mempengaruhi durasi waktu menonton anak dan menyalakan televisi lebih lama. Kondisi ini harus menjadi perhatian orang tua siswa, karena menonton televisi terlalu lama akan berdampak pada tingkat pengetahuan (Ridwan \& Prasetya, 2015) dan perkembangan perilaku sosial anak (Astarini, Hamid, \& Rustini, 2017). Terkait gadget, survei Uswitch mengungkap bahwa 3,5 juta anak di bawah usia 8 tahun telah kecanduan gadget, sedangkan penelitian Sucipto dan Nuril pada 2016 mengungkap bahwa 54\% orang tua telah membolehkan anak mereka bermain gadget pada usia 3-4 tahun dengan beragam alasan diantaranya mengenalkan anak pada teknologi, agar anak tidak rewel, dan karena faktor sosial (Khuzma \& La Kahija, 2017).

Terkait dengan air, terdapat sekitar 32,7\% siswa yang masih banyak menyia-nyiakan air dengan tidak menutup keran air secara benar setelah digunakan (item 9). Hal ini akan mengakibatkan konsumsi air tanah meningkat dan mengurangi cadangan air di bumi. Selain itu penggunaan air secara berlebihan juga mengakibatkan naiknya konsumsi listrik pada saat air 
yang digunakan memanfaatkan tenaga pompa listrik atau air PAM. Di sisi yang lain hanya sedikit siswa $(32,7 \%)$ yang memanfaatkan air hujan untuk keperluan yang lain walaupun hanya sekedar menyiram tanaman (item 10). Berkenaan dengan sampah, sekitar $35 \%$ siswa membuang sampah tanpa memilahnya (item 12). Padahal sampah terbesar yang dihasilkan oleh anak adalah berupa plastik dari ragam sumber seperti bungkus mainan, mainan rusak, dan bungkus makanan/camilan dan minuman. Hal ini berpotensi menyebabkan volume sampah terutama plastik meningkat karena hampir semua mainan, camilan ataupun minuman anak terbuat dari bahan plastik dan dibungkus menggunakan plastik yang pasti akan mencemari lingkungan dalam waktu lama. Sampah plastik di Indonesia telah menjadi masalah serius, penelitian Jambeck tahun 2015 menyatakan bahwa Indonesia adalah negara peringkat kedua terbesar di dunia setelah China sebagai penghasil sampah plastik di perairan dengan jumlah mencapai 187,2 juta ton (Purwaningrum, 2016).

\section{Literasi Low Carbon Anak Usia 12 Tahun (Kelas 6)}

\section{Literasi Low Carbon Siswa Kelas 6}

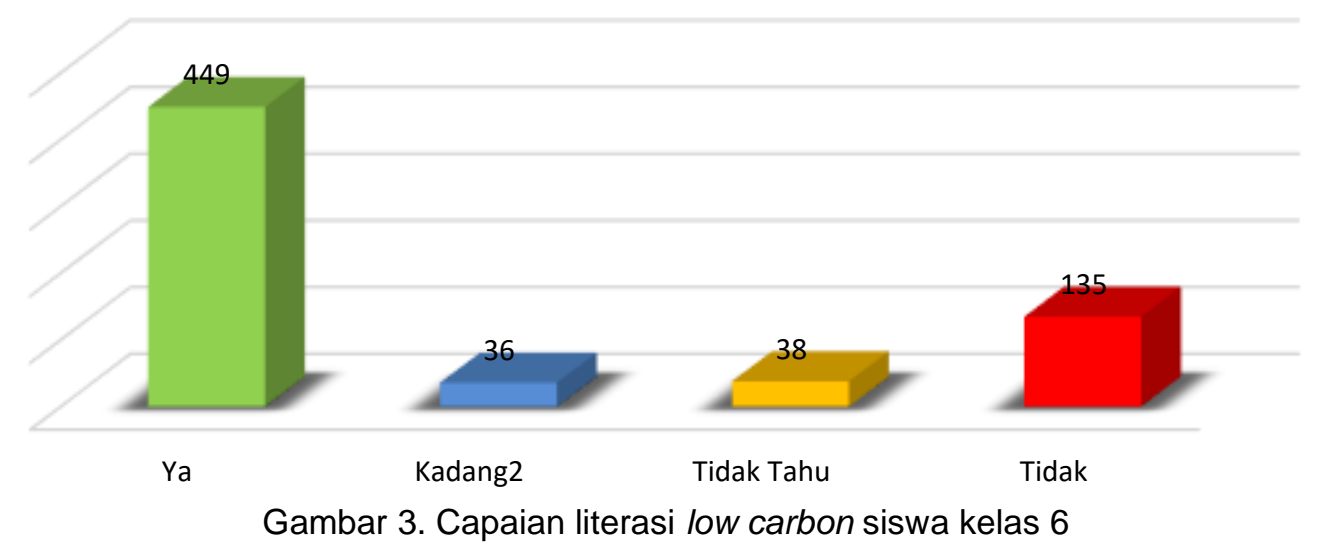

Secara umum, sebagian besar siswa kelas 6 telah mempraktikkan perilaku low carbon dalam berbagai aktivitas kehidupan mereka, dan terdapat hanya $20,5 \%$ siswa yang belum mengaplikasikan prinsip low carbon dalam aktivitas kesehariannya. Pada aktivitas yang terkait dengan penggunaan energi seperti mematikan televisi dan lampu saat tidak dipakai, prosentase siswa yang telah mengaplikasikan itu sangat tinggi berkisar antara $91 \%$ (item 1) dan $95,7 \%$ (item 2). Pada aspek pemanfaatan air, terlihat bahwa $87 \%$ siswa kelas 6 tidak membiarkan air terbuang percuma dalam aktivitas kesehariannya seperti mandi dan gosok gigi (item 7-9). Kondisi ini menyiratkan bahwa nilai-nilai dari prinsip low carbon telah telah tertanam dalam diri siswa sehingga mampu teraplikasi dalam aktivitas keseharian mereka. Fakta ini tentu tidak bisa kita lepaskan dari pendidikan tentang lingkungan yang mereka dapatkan disekolah dan dirumah. Peran pendidikan lingkungan oleh orang tua dirumah dan guru disekolah sangat penting untuk membentuk karakter peduli lingkungan dalam diri siswa semenjak usia dini (Masruroh, 2018). Oleh karena optimalisasi pendidikan sains dengan memasukkan muatan-muatan low carbon education seperti green energy, green technology, efek rumah kaca, pemanasan global, dan pengolahan sampah kita harapkan akan semakin memperkuat daya dorong pendidikan sains untuk membentuk manusia dan masyarakat yang peduli lingkungan dan sustainability. 


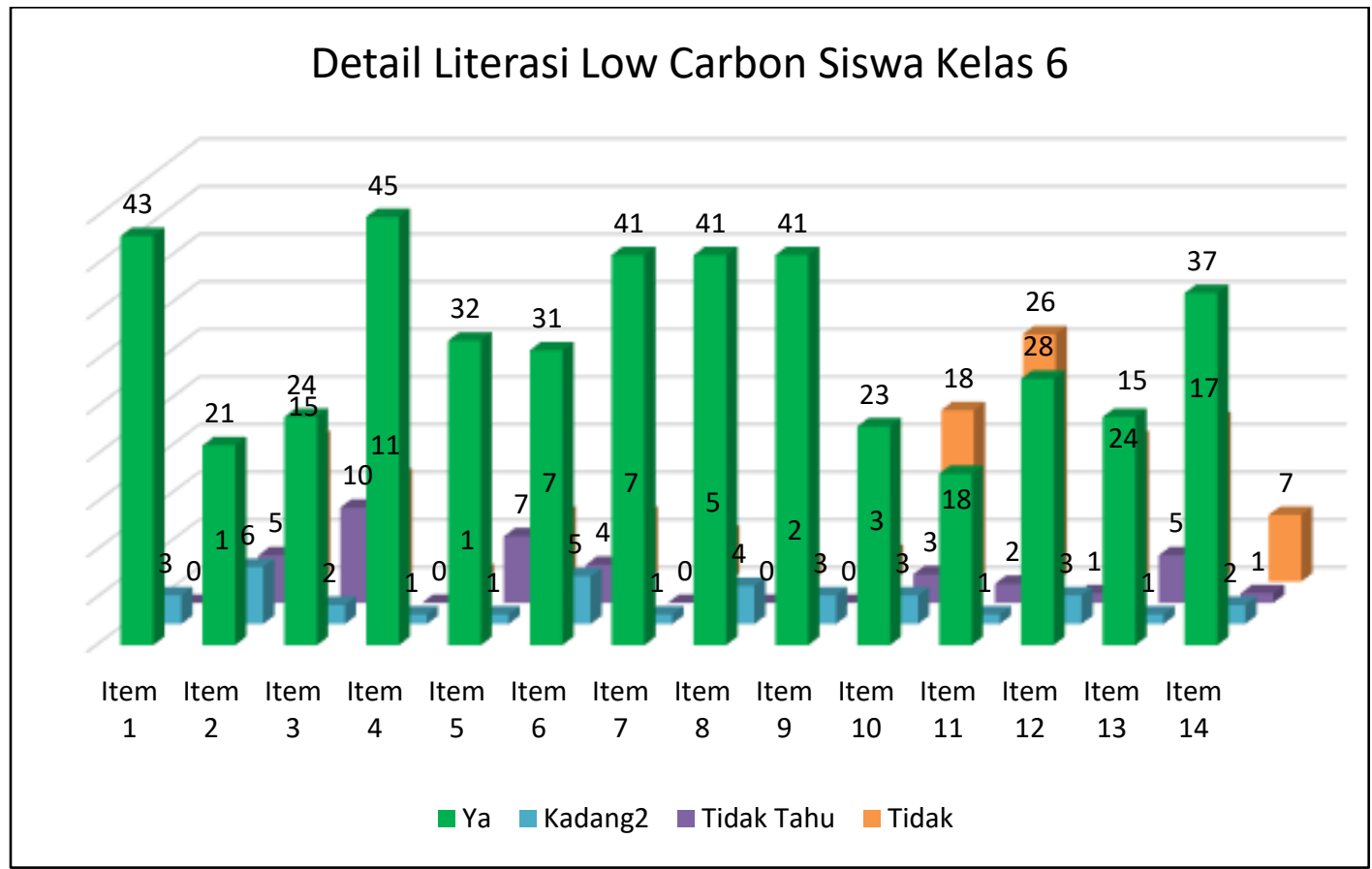

Gambar 4. Literasi low carbon siswa kelas 6 per item pertanyaan

Seiring dengan perkembangan daya pikir dan juga banyaknya pengetahuan yang telah mereka dapatkan selama proses sekolah hingga mencapai kelas 6 , terlihat bahwa semakin sedikit pula aktivitas yang dilakukan oleh siswa yang bertentangan dengan nilai-nilai low carbon. Namun pada beberapa aktivitas yang dijalani siswa, perhatian serta bimbingan lebih harus tetap diberikan agar sesuai dengan prinsip low carbon yaitu pertama, perilaku mencabut kabel dari stop kontak sebelum tidur (item 2) di mana terdapat 55\% siswa yang membiarkan peralatan listrik seperti televisi dan komputer tetap terpasang pada stop kontak. Hal ini kemungkinan besar akibatkan dari pembiasaan oleh orang tua karena ketakutan mereka melihat anaknya bermain atau bersentuhan dengan listrik. Pembiasaan merupakan salah satu cara terbaik dalam mendidik serta membentuk karakter dalam diri anak (Ayun, 2017). Kedua, menyalakan pendingin ruangan selama 24 jam (item 3), ada 49\% siswa yang selalu membiarkan pendingin ruangan tetap menyala selama 24 jam dan $21 \%$ siswa yang kemungkinan tidak paham tentang hal tersebut dan tampak negatifnya. Namun, perilaku ini mungkin saja dipengaruhi faktor geografis di mana siswa tinggal didaerah pedesaan yang tidak memiliki pendingin ruangan di rumahnya.

Ketiga, perilaku mandi menggunakan air dan bathtub (item 10) masih ada 44,7\% siswa yang masih boros menggunakan air ketika mandi menggunakan bathtub. Dalam hal ini siswa masih sangat perlu untuk dipahamkan lagi bahwa perilaku seperti ini bisa mengurangi cadangan air dalam tanah dan kalau perilaku ini terus dilakukan akan menyebabkan krisis air dibumi. Keempat, berkenaan dengan penggunaan kantong plastik ketika berbelanja (item 11), masih terdapat 38\% siswa yang masih menggunakan kantong plastik untuk membungkus makanan atau barang belanjaannya. Kelima, lagi-lagi terkait dengan sampah, 46,8\% siswa kelas 6 masih belum bisa mengurangi volume sampah yang mereka buang setiap harinya (item 13).

\section{PENUTUP}

Dari data yang didapat dan analisis yang dilakukan terlihat bahwa sebagian besar siswa sekolah dasar di Kabupaten Lombok Timur telah mampu mengaplikasikan prinsip dan nilai low carbon education dalam aktivitas kehidupan sehari-hari mereka. Secara umum siswa kelas 6 
memiliki literasi low carbon sedikit lebih baik dibandingkan dengan siswa kelas 3 . Hal ini mengindikasikan adanya pengaruh faktor tingkat perkembangan siswa terhadap level literasi low carbon siswa, namun hal ini perlu dibuktikan melalui penelitian lebih lanjut. Literasi low carbon anak usia 9 tahun (kelas 3 ) terlihat kurang pada 8 item aktivitas yang terkait dengan konteks penggunaan listrik (televisi dan gadget), air, dan sampah terutama plastik. Sementara perilaku literasi low carbon yang menjadi titik kekurangan siswa kelas 6 ialah pada 5 item aktivitas yaitu membiarkan alat listrik tetap tersambung dengan stop kontak, penggunaan pendingin ruangan, perilaku boros air ketika mandi, penggunaan kantong plastik dan sampah.

\section{DAFTAR PUSTAKA}

Afriyeni, Y. (2018). Pembentukan Karakter Anak Untuk Peduli Lingkungan Yang Ada Di Sekolah Adiwiyata Mandiri SDN 6 Pekanbaru Yeni Afriyeni Sekolah Tinggi Persada Bunda Pekanbaru. Jurnal PAUD Lectura, 1(2).

Amin, M. S., Permanasari, A., \& Setiabudi, A. (2019). Strengthen the student environmental literacy through education with low carbon education teaching materials. Journal of Physics: Conference Series, 1280(3). https://doi.org/10.1088/1742-6596/1280/3/032011

Amin, M Syahruddin, Permanasari, A., \& Setiabudi, A. (2019). The Pattern of Environmental Education Practice at Schools and Its Impact toThe Level of Environmental Literacy of School-age Student. IOP Conference Series: Earth and Environmental Science. https://doi.org/10.1088/1755-1315/245/1/012029

Amini, R. (2015). Outdoor based environmental education learning and its effect in caring attitude toward environment. Jurnal Pendidikan IPA Indonesia, 4(1), 43-47. https://doi.org/10.15294/jpii.v4i1.3500

Astarini, N., Hamid, S. I., \& Rustini, T. (2017). Studi Dampak Tayangan Televisi Terhadap Perkembangan Perilaku Sosial Anak. Jurnal Cakrawala Dini, 8(1). https://doi.org/http://dx.doi.org/10.17509/cd.v8i1.10554

Ayun, Q. (2017). Pola Asuh Orang Tua dan Metode Pengasuhan dalam Membentuk Kepribadian Anak. Jurnal ThufuLa, 5(1), 102-122. https://doi.org/http://dx.doi.org/10.21043/thufula.v5i1.2421

BP Energy. (2018). British Petroleum Energy Outlook 2018. In BP Energy Economics. https://doi.org/10.1088/1757-899X/342/1/012091

BPPT. (2018). Outlook Energi Indonesia 2018; Energi Berkelanjutan Untuk Transportasi Darat. In Pusat Pengkajian Industri Proses dan Energi (Vol. 134). https://doi.org/10.1360/zd-201343-6-1064

Capuano, L. (2018). International Energy Outlook 2018 (IEO2018). 2018, 21.

Dawson, V. (2015). Western Australian High School Students' Understandings about the Socioscientific Issue of Climate Change. International Journal of Science Education, 37(7), 1024-1043. https://doi.org/10.1080/09500693.2015.1015181

Gola, B. (2017). Is formal environmental education friendly to nature? Environmental ethics in science textbooks for primary school pupils in Poland. Ethics and Education, 12(3), 320336. https://doi.org/10.1080/17449642.2017.1343619

Hamzah, S. (2013). Pendidikan Lingkungan; Sekelumit Wawasan Pengantar (1st ed.; A. Gunarsa, Ed.). Bandung: Refika Aditama.

Khuzma, R. R., \& La Kahija, Y. F. (2017). Pengalaman menjadi ibu di era digital: interpretative phenomenological analysis. Jurnal Empati, 6(4), 387-395.

Mardani, A., Streimikiene, D., Cavallaro, F., Loganathan, N., \& Khoshnoudi, M. (2019). Carbon Dioxide (CO2) Emission and Economic Growth: A Systematic Review of Two Decades of Research from 1995 to 2017. Science of the Total Environment, 649, 31-49. 


\section{Menakar Level Literasi Low Carbon Siswa Sekolah Dasar ... \\ M. Syahruddin Amin, Anna Permanasari, Agus Setiabudi, Ida Hamidah}

https://doi.org/10.1016/j.scitotenv.2018.08.229

Masruroh. (2018). Membentuk Karakter Peduli Lingkungan Dengan Pendidikan. Jurnal Geografi Gea, 18(2), 130-134. https://doi.org/http://dx.doi.org/10.17509/gea.v18i2.13461

Nurcahyani, A. (2015). Pola Perilaku Menonton Televisi pada Anak Berperilaku Agresif di Kelompok B TK Dharma Bhakti IV Ngebel Kasihan Bantul. Universitas Negeri Yogyakarta.

Paige, K. (2016). Educating for sustainability: environmental pledges as part of tertiary pedagogical practice in science teacher education. Asia-Pacific Journal of Teacher Education, 45(3), 285-301. https://doi.org/10.1080/1359866X.2016.1169504

Priyatna, A., Meilinawati, L., \& Subekti, M. (2017). Pengenalan Pola Hidup Berwawasan Lingkungan pada Ibu dan Anak di PAUD Siti Fatimah Kota Cirebon. Jurnal Pengabdian Kepada Masyarakat, 1(6), 348-351.

Purwaningrum, P. (2016). Upaya Mengurangi Timbunan Sampah Plastik di Lingkungan. Jurnal Teknologi Lingkungan, 8(2), 141-147. https://doi.org/http://dx.doi.org/10.25105/urbanenvirotech.v8i2.1421

Ridwan, A., \& Prasetya, T. (2015). Dampak Sering Menonton Televisi pada Anak Usia Sekolah. Jurnal AKP, 6(1), 41-46.

Xiaowei, Y., \& Xing, J. (2011). Low-carbon Economy and Low-carbon Food. Energy Procedia, 5, 1099-1103. https://doi.org/10.1016/j.egypro.2011.03.193

Zheng, L., Zhou, Z., \& Shi, Y. (2014). Developing Low Carbon Education and Advocating Low Carbon Lifestyles in Universities. International Conference on Social Science and Environmental Protection (SSEP), 360-367. Shanghai, China. 